\title{
A retrospective comparison of Escherichia coli and polyethylene glycol-conjugated asparaginase for the treatment of adolescents and adults with newly diagnosed acute lymphoblastic leukemia
}

\author{
JIABAO LIANG ${ }^{1,2^{*}}$, PENGCHENG SHI $^{1 *}$, XUTAO GUO $^{1 *}$, JIE LI $^{1}$, LINGLI HE $^{1}$, \\ YAN WANG $^{1}$, QI WEI ${ }^{1}$, FEN HUANG $^{1}$, ZHIPING FAN $^{1}$ and BING XU ${ }^{3}$
}

\begin{abstract}
${ }^{1}$ Department of Hematology, Nanfang Hospital, Southern Medical University, Guangzhou, Guangdong 510515; ${ }^{2}$ Department of Hematology, The First People Hospital of Foshan, Affiliated Hospital of Sun Yat-Sen University, Foshan, Guangdong 528000;

${ }^{3}$ Department of Hematology, The First Affiliated Hospital of Xiamen University, Xiamen, Fujian 361003, P.R. China
\end{abstract}

Received December 10, 2015; Accepted May 16, 2017

DOI: $10.3892 / \mathrm{ol} .2017 .7271$

\begin{abstract}
Data from clinical trials suggest that polyethylene glycol-conjugated asparaginase (PEG asparaginase) should be recommended as a replacement for Escherichia coli (E. coli) asparaginase in the treatment of pediatric acute lymphoblastic leukemia (ALL) due to its prolonged effect, similar safety profile and convenience. The present study investigated the efficacy and safety of PEG asparaginase in adolescents and adults with newly diagnosed ALL. The clinical data of 122 patients, $\geq 14$ years old with de novo ALL, who received either PEG asparaginase or E. coli asparaginase as part of an induction regimen, were retrospectively analyzed. The results revealed that PEG asparaginase had a comparable complete remission rate (95.65 vs. $90.79 \%$ ), median overall survival time (14.07 vs. 16.29 months) and median relapse-free survival time (10.00 vs. 8.57 months) with $E$. coli asparaginase. In addition, patients $<35$ years old receiving PEG asparaginase obtained a higher median RFS time compared with those receiving E. coli
\end{abstract}

Correspondence to: Professor Bing Xu, Department of Hematology, The First Affiliated Hospital of Xiamen University, 55 Zhenhai Road, Xiamen, Fujian 361003, P.R. China

E-mail: xubingzhangjian@126.com

*Contributed equally

Abbreviations: PEG asparaginase, polyethylene glycol-conjugated asparaginase; E. coli asparaginase, Escherichia coli asparaginase; ALL, acute lymphoblastic leukemia; CR, complete remission; OS, overall survival; RFS, relapse-free survival; EFS, event-free survival; CNSL, central nervous system leukemia; NCCN, National Comprehensive Cancer Network; allo-BMT, allogeneic bone marrow transplant; ULN, upper limit of normal; CSF, cerebrospinal fluid

Key words: polyethylene glycol-conjugated asparaginase, Escherichia coli asparaginase, acute lymphoblastic leukemia, efficacy asparaginase (10.93 vs. 8.97 months; $\mathrm{P}=0.037$ ). Patients treated with $E$. coli asparaginase exhibited a significantly higher incidence of central nervous system leukemia (CNSL) compared with those treated with PEG asparaginase (27.63 vs. $10.87 \%$; $\mathrm{P}=0.028$ ) during the consolidation phase. Toxic events, including allergy, grade III-IV liver dysfunction, renal function damage and pancreatic lesions were similar between the two groups. A longer duration of coagulation dysfunction $(9.80 \pm 5.51$ vs. $6.80 \pm 4.21$ days; $\mathrm{P}=0.002)$ and agranulocytosis $(18.89 \pm 8.79$ vs. $12.03 \pm 8.34$ days; $\mathrm{P}<0.01)$, and a higher incidence of grade IV-V infections ( 22.73 vs. $7.25 \%$; $\mathrm{P}=0.018$ ) were observed in the PEG asparaginase group. However, these did not increase bleeding events or infection-associated mortalities. When taking the convenience and superior efficacy in preventing CNSL into consideration, PEG asparaginase is a candidate for first-line treatment of adolescent and adult ALL. A larger prospective clinical trial is required to further confirm this point of view.

\section{Introduction}

Asparaginase is one of the major anticancer drugs used in the treatment of acute lymphoblastic leukemia (ALL) $(1,2)$. This drug hydrolyzes the amino acid asparagine to aspartic acid and ammonia to deplete asparagine in the blood, inducing the malignant lymphoid cells that depend on extracellular asparagine to enter into apoptosis (2). The overall survival (OS) rate is $\sim 90 \%$ in pediatric patients with ALL and only $30 \%$ in adult patients with ALL $(3,4)$. One of the differences between pediatric and adult treatment regimens is the intensive use of asparaginase in pediatric regimens. Intensified use of asparaginase increases event-free survival (EFS) for children with ALL by $10-15 \%$ (5-7). Adolescent and adult patients receiving pediatric-based regimens with greater use of asparaginase have also achieved better outcomes (8-10). However, they are more prone to severe grade 3-4 toxicities, including thrombosis, pancreatitis and chemical hepatitis, compared with pediatric patients intensively using asparaginase (11). Therefore, the investigation of novel preparations of asparaginase is essential. 
Polyethylene glycol-conjugated asparaginase (PEG asparaginase) is formed by the polyethylene glycosylation of the Escherichia coli (E. coli)-derived enzyme, resulting in a longer circulating half-life and lower immunogenicity, which decreases the incidence of allergic reactions and anti-asparaginase antibody formation $(12,13)$. PEG asparaginase has been recommended as a replacement for E. coli asparaginase in the treatment of pediatric ALL due to its prolonged effect, similar safety profile and convenience (14). In addition, considering the decreased number of doses and clinic visits, the total patient costs of PEG asparaginase are comparable with those of native E. coli asparaginase (15). However, only a few clinical studies have compared the efficacy and safety of PEG asparaginase with native $E$. coli asparaginase in adolescent and adult patients with ALL. The present study retrospectively compared the relative efficacy and safety of PEG asparaginase and $E$. coli asparaginase in adolescent and adult patients newly diagnosed with ALL.

\section{Materials and methods}

Patients. A total of 122 patients who were $\geq 14$ years old with de novo ALL and had received treatment at the Department of Hematology, Nanfang Hospital (Guangzhou, China) between January 2008 and July 2015 were included in this retrospective study, including 46 patients in the PEG asparaginase group and 76 in the E. coli asparaginase group. There were 76 males and 46 females, the median age of these patients was 27.4 years (ranged from 14 to 62 years). ALL and central nervous system leukemia (CNSL) cases were diagnosed based on the National Comprehensive Cancer Network (NCCN) Clinical Practice Guidelines in Oncology: Acute Lymphoblastic Leukemia (version 1, 2015) (16). Patients with liver dysfunction, renal function damage or other organ dysfunctions prior to induction therapy were excluded. Clinical data, including the patients' characteristics, response to chemotherapy and adverse effects experienced in association with asparaginase preparations, were retrospectively analyzed. Ethical approval was obtained from the Ethics Committee of Nanfang Hospital. Written informed consent was obtained from all patients or their family members prior to enrollment in the present study.

Treatment. Patients with newly diagnosed ALL in Nanfang Hospital were administered a standard four-drug induction regimen containing vincristine at $1.4 \mathrm{mg} / \mathrm{m}^{2} / \mathrm{day}$, with a maximum of $2 \mathrm{mg} / \mathrm{day}$, or vindesine at $4 \mathrm{mg} / \mathrm{day}$ on days $1,8,15$ and 22 ; daunorubicin at $40 \mathrm{mg} / \mathrm{m}^{2} /$ day or idarubicin at $8 \mathrm{mg} / \mathrm{m}^{2} /$ day on days $1,8,15$ and $22 ; E$. coli asparaginase at $6,000 \mathrm{IU} / \mathrm{m}^{2}$ once every 2 days from day 17 to 28 or PEG asparaginase at $2,500 \mathrm{IU} / \mathrm{m}^{2}$ on day 22 ; and prednisone $1 \mathrm{mg} / \mathrm{kg} / \mathrm{day}$ on days $1-28$. Either E. coli asparaginase or PEG asparaginase were used based on the patients' approval. Philadelphia chromosome-positive patients with ALL received tyrosine kinase inhibitors as long as the Philadelphia chromosome was observed. Patients who went into $\mathrm{CR}$ received consolidation chemotherapy for 2-4 commutative courses of the Hyper CVAD-A/B regimen: Odd courses $(1,3,5$ and 7$)$ of hyper-fractionated cyclophosphamide (Cytoxan), doxorubicin (Adriamycin), vincristine
(Oncovin) and dexamethasone were given alternately with even courses (2, 4, 6 and 8) of high-dose cytarabine and methotrexate. Lumbar puncture and CNSL prophylaxis was provided during every consolidation therapy. A total of 51 patients with human-leukocyte-antigen-matched donors underwent an allogeneic bone marrow transplant (allo-BMT) and 4 patients underwent an autologous bone marrow transplant in CR1. A total of 7 relapsed patients and 2 patients with no response following continuous chemotherapy underwent an allo-BMT.

Response criteria. The patients' responses to chemotherapy were assessed on day $14 \pm 2$ and at the end of induction chemotherapy. The treatment efficacy was also evaluated according to the 2015 NCCN Guidelines (16). Remission also required normal marrow cellularity and elements. Follow-up was performed for the patients in the clinic or by telephone, and the median follow-up occurred at 15.4 months. Overall survival was determined from ALL diagnosis to mortality or the final follow-up. Relapse-free survival (RFS) was determined from the first CR to relapse, mortality or the final follow-up.

Adverse events. All of the adverse events were graded according to the National Cancer Institute Common Terminology Criteria for Adverse Events, version 4.03 (17). Coagulation disorder was defined as an activated partial thromboplastin time prolonged by $>10 \mathrm{sec}$ over its upper limit of normal (ULN, 31-43 sec), a thromboplastin time prolonged by $>3 \mathrm{sec}$ over its ULN $(11-13 \mathrm{sec})$ or a fibrinogen level $<1.5 \mathrm{~g} / 1(2-4 \mathrm{~g} / \mathrm{l})$.

Statistical analysis. All of the evaluations were performed using SPSS version 18.0 software (SPSS Inc., Chicago, IL, USA). The descriptive statistical values included mean \pm standard deviation, median and range. Comparisons of the various groups were performed using Student's t-test, Wilcoxon's rank sum test, $\chi^{2}$ test or Fisher's exact test. Comparisons of baseline clinical variables across groups were made using the $\chi^{2}$ test or Fisher's exact test for categorical data and constituent ratio; Wilcoxon's rank sum test was applied for ranked data. Mean comparisons between two groups were performed using Spearman's rank. OS curves were estimated using the Kaplan-Meier method. Comparisons of different survival curves were performed using log-rank test. Two-sided $\mathrm{P}<0.05$ was considered to indicate a statistically significant difference.

\section{Results}

Patient characteristics. Of the 122 patients enrolled in the study, 46 were treated with PEG asparaginase and 76 were treated with $E$. coli asparaginase. Table I displays the pretreatment characteristics of the study group. The two groups were well balanced in terms of their pretreatment characteristics, including age, initial white blood cell count, bone marrow blast, extramedullary invasion, immunophenotype, molecular biology aberration and chromosome characteristics (Table I). Furthermore, 25 of the 46 patients in the PEG asparaginase group and 39 of the 76 patients in the E. coli asparaginase group underwent hematopoietic stem cell transplantation. 
Table I. Baseline patient characteristics.

\begin{tabular}{|c|c|c|c|}
\hline Characteristic & $\begin{array}{l}\text { PEG asparaginase } \\
\qquad(\mathrm{n}=46)\end{array}$ & $\begin{array}{l}\text { E. coli asparaginase } \\
\qquad(\mathrm{n}=76)\end{array}$ & P-value \\
\hline Total patients, $\mathrm{n}$ & 46 & 76 & \\
\hline Median age (range), years & $26(14-62)$ & $23(14-56)$ & 0.262 \\
\hline \multicolumn{4}{|l|}{$\operatorname{Sex}, \mathrm{n}(\%)$} \\
\hline Male & $30(65.22)$ & $46(60.53)$ & 0.604 \\
\hline Female & $16(34.78)$ & $30(39.47)$ & \\
\hline Median WBC (range), x109/1 & $22.61(1.24-395.65)$ & $13.37(0.54-435)$ & 0.146 \\
\hline Hemoglobin, g/l & $84.92 \pm 28.18$ & $90.14 \pm 33.54$ & 0.379 \\
\hline Platelet (range), $\times 10^{9} / 1$ & $40(6-173)$ & $38.5(4-289)$ & 0.996 \\
\hline Bone marrow lymphoblast \% (range) & $87.45(26-100)$ & $90(24.5-99.5)$ & 0.574 \\
\hline Extramedullary invasion, n (\%) & $22(47.83)$ & $45(59.21)$ & 0.221 \\
\hline Immunophenotype, n (\%) & & & 0.745 \\
\hline B-ALL & $37(80.43)$ & $64(84.21)$ & \\
\hline T-ALL & $7(15.22)$ & $8(10.53)$ & \\
\hline Unknown & $2(4.35)$ & $4(5.26)$ & \\
\hline \multicolumn{4}{|l|}{ Molecular biology aberration, n (\%) } \\
\hline $\mathrm{BCR} / \mathrm{ABL}$ & $7(15.22)$ & $19(25.00)$ & 0.201 \\
\hline P16 depletion & $10(21.74)$ & $12(15.79)$ & 0.407 \\
\hline MLL rearrangement & $3(6.52)$ & $1(1.32)$ & 0.150 \\
\hline IGH rearrangement & $3(6.52)$ & $3(3.95)$ & 0.671 \\
\hline Chromosome, n (\%) & & & 0.705 \\
\hline $\mathrm{Ph}$ & $6(13.04)$ & $16(21.05)$ & \\
\hline Complex karyotype & $3(6.52)$ & $4(5.26)$ & \\
\hline Hyperdiploidy & $1(2.17)$ & $4(5.26)$ & \\
\hline Hypodiploidy & $1(2.17)$ & $1(1.32)$ & \\
\hline Normal & $30(65.22)$ & $40(52.63)$ & \\
\hline No mitotic phase & $5(10.87)$ & $11(14.47)$ & \\
\hline Transplantation, $\mathrm{n}(\%)$ & $25(53.35)$ & $39(51.32)$ & 0.745 \\
\hline
\end{tabular}

Extramedullary invasion included hepatomegaly, splenomegaly, lymphadenectasis or any other tissue leukemia invasion. WBC, white blood cell; PEG asparaginase, polyethylene glycol-conjugated asparaginase; ALL, acute lymphoblastic leukemia; B-ALL, B-cell ALL; T-ALL, T-cell ALL; BCR, BCR, RhoGEF and GTPase activating protein; ABL, V-Abl Abelson Murine Leukemia Viral Oncogene; MLL, mixed lineage luekemia; IGH, immunoglobulin heavy chain; E. coli, Escherichia coli; Ph, Philadelphia chromosome.

Response to induction therapy. Overall, 113 (92.62\%) patients achieved CR following the induction of chemotherapy. As presented in Table II, 44 of the 46 patients in the PEG asparaginase group (95.65\%) and 69 of the 76 patients in the E. coli asparaginase group (90.79\%) achieved CR. Table II also presents the median times taken to achieve CR; 30 days for the PEG asparaginase group and 29.5 days for the E. coli asparaginase group.

PEG asparaginase is superior to E. coli asparaginase at preventing CNSL. During the consolidation phase, CNSL occurred in 5 of the 46 patients $(10.87 \%)$ in the PEG asparaginase group and 21 of the 76 patients $(27.63 \%)$ in the E. coli asparaginase group. The incidence of CNSL in the E. coli asparaginase group was significantly higher compared with that in the PEG asparaginase group $(\mathrm{P}=0.028$; Table II), suggesting that PEG asparaginase had a potential role in preventing CNSL.
OS and RFS. As 1 patient in the PEG asparaginase group succumbed to mortality due to severe pulmonary infection after achieving CR, there were 45 patients to follow-up. As presented in Fig. 1A and B, at a median follow-up of 15.4 months, the median RFS time was 10.00 months (range, 0.5-50.70 months) for the PEG asparaginase group and 8.57 months (range, 0-76.83 months) for the E. coli asparaginase group ( $\mathrm{P}=0.220$; Fig. $1 \mathrm{~A})$. In addition, the median $\mathrm{OS}$ time for the PEG asparaginase group was 14.07 months (range, 2.27-52.47 months) and that for the E. coli asparaginase group was 16.29 (range, 1.80-79.90) months ( $\mathrm{P}=0.972$; Fig. 1B). The present study observed no significant difference in RFS and OS times between the two groups. However, patients $<35$ years old in the PEG asparaginase group obtained a longer median RFS time of 10.93 months (range, 0.5-50.70 months) compared with those in the $E$. coli asparaginase group, who had a time of 8.97 months (range, 0-76.83 months) $(\mathrm{P}=0.037$; Fig. 2A); the median OS time was not significantly different 
Table II. Response to induction therapy.

\begin{tabular}{lcc}
\hline Response & PEG asparaginase & E. coli asparaginase \\
$(\mathrm{n}=46)$ & $76)$ & $69(90.79)$ \\
CR, $\mathrm{n}(\%)$ & $44(95.65)$ & $29.50(13-203)$ \\
Time to achieve CR (range), days & $30(12-94)$ & $21(27.63)$ \\
CNSL in consolidation phase, $\mathrm{n}(\%)$ & $5(10.87)$ & 0.481 \\
\hline
\end{tabular}

CR, complete remission; CNSL, central nervous system leukemia; PEG asparaginase, polyethylene glycol-conjugated asparaginase; E. coli, Escherichia coli.
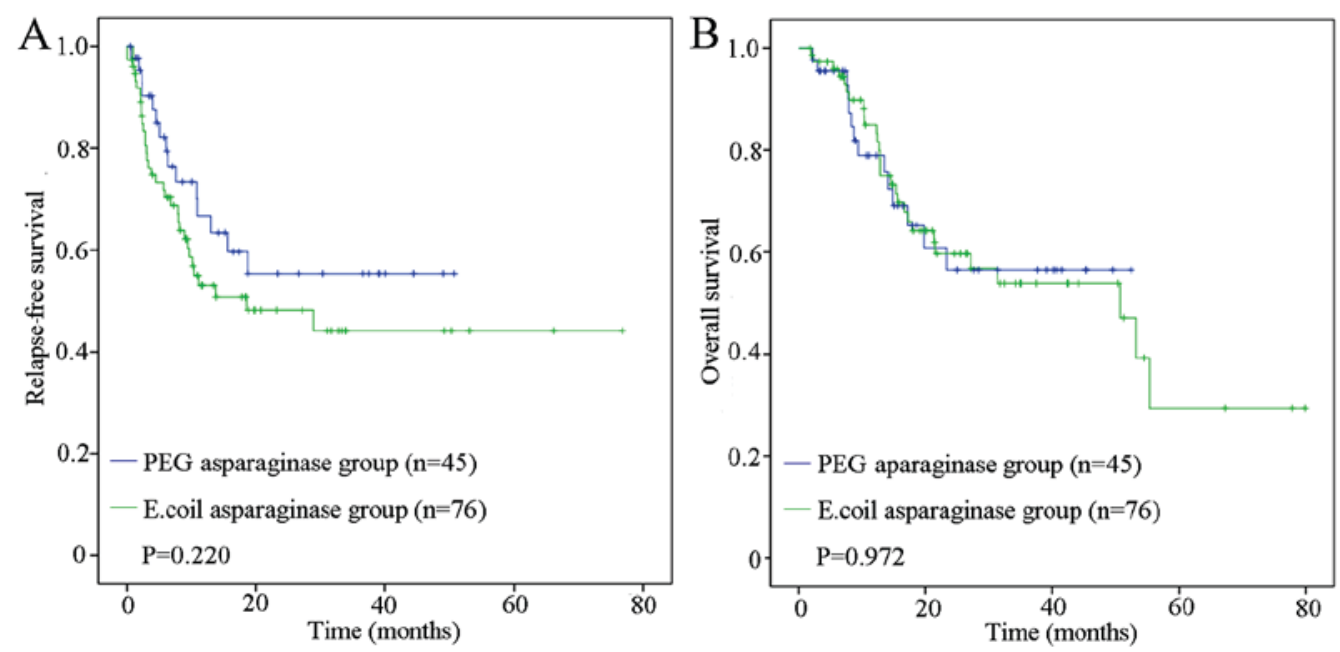

Figure 1. Kaplan-Meier estimates of RFS and OS for all patients. (A) RFS for all patients. (B) OS for all patients. RFS, relapse-free survival; OS, overall survival; PEG asparaginase, polyethylene glycol-conjugated asparaginase.

at 14.07 months (range, 2.27-52.47 months) for the PEG asparaginase group and 17.63 months $(1.80-79.90$ months) for the $E$. coli asparaginase group ( $\mathrm{P}=0.671$; Fig. $2 \mathrm{~B})$. For patients $\geq 35$ years old, the PEG asparaginase and $E$. coli asparaginase groups had a similar median RFS time of 6.32 months (range, 1.37-40.10 months) and 6.73 months (range, 0.7-49.20 months), respectively $(\mathrm{P}=0.597)$, and a similar OS time of 14.17 months (range, 2.27-41.53 months) and 12.77 months (range, 2.33-50.37 months), respectively $(\mathrm{P}=0.693)$, (Fig. 3A and $\mathrm{B})$.

Toxicity. Table III presents the toxic events observed during the asparaginase-containing phases of chemotherapy. Overall, the toxicities of asparaginase were tolerable in the two groups. The incidences of allergy, grade III-IV liver dysfunction, renal function damage and pancreatic lesions were similar between the two groups. Patients in the PEG asparaginase group demonstrated a longer duration of coagulation dysfunction (9.80 \pm 5.51 vs. $6.80 \pm 4.21$ days; $\mathrm{P}=0.002)$ compared with those in the E. coli asparaginase group. However, the present study observed no significant difference in bleeding events between the two groups ( 8.70 vs. $3.95 \%$; $\mathrm{P}=0.424)$. The grade of myelosuppression between the two groups was similar for patients who achieved CR; however, the duration of agranulocytosis was significantly longer for the patients treated with PEG asparaginase compared with those in the E. coli asparaginase group $(18.89 \pm 8.79$ vs. $12.03 \pm 8.34$ days; $\mathrm{P}<0.001)$. Consistent with the difference in agranulocytosis duration, the patients who received PEG asparaginase revealed a higher incidence of grade IV-V infection compared with those who received E. coli asparaginase (22.73 vs. $7.25 \% ; \mathrm{P}=0.018)$. However, this did not increase the incidence of infection-associated mortality.

\section{Discussion}

Asparaginase is an essential and routinely used component in the frontline clinical treatment for ALL (1). However, administration of asparaginase can be limited by the occurrence of anaphylaxis and formation of antibodies to asparaginase. Studies have indicated that patients with high-titer asparaginase antibodies demonstrate an increased rate of clearance and degrade the activity of the agent, resulting in poorer EFS $(18,19)$. Patients who exhibit these reactions are switched to another asparaginase product to ensure they are exposed to a high enough dosage of asparaginase in accordance with the treatment plan to obtain the optimal EFS. Due to its polyethylene glycol covalent conjugation, PEG asparaginase has decreased levels of renal excretion, a prolonged half-life, improved bioavailability, decreased immunogenicity and a reduced frequency of administration, making it an alternative to L-asparaginase $(12,20,21)$. Previous clinical trials 

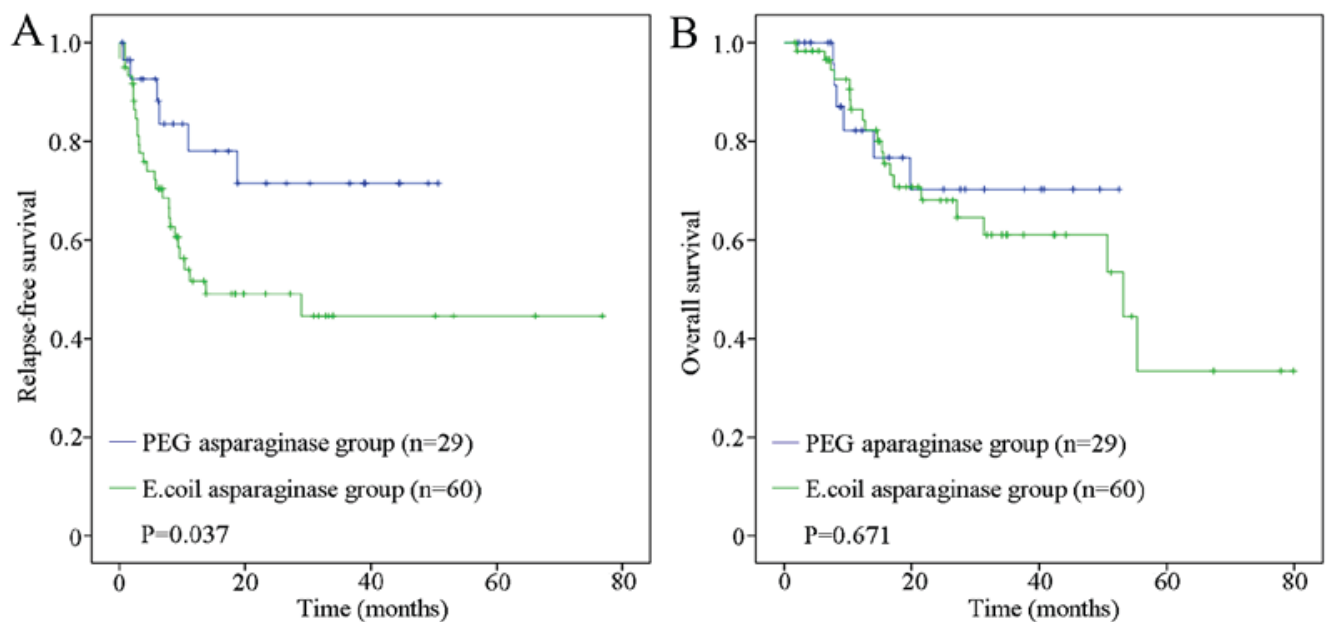

Figure 2. Kaplan-Meier estimates of RFS and OS in patients $<35$ years old. (A) RFS in patients $<35$ years old. (B) OS in patients $<35$ years old. RFS, relapse-free survival; OS, overall survival; PEG asparaginase, polyethylene glycol-conjugated asparaginase.
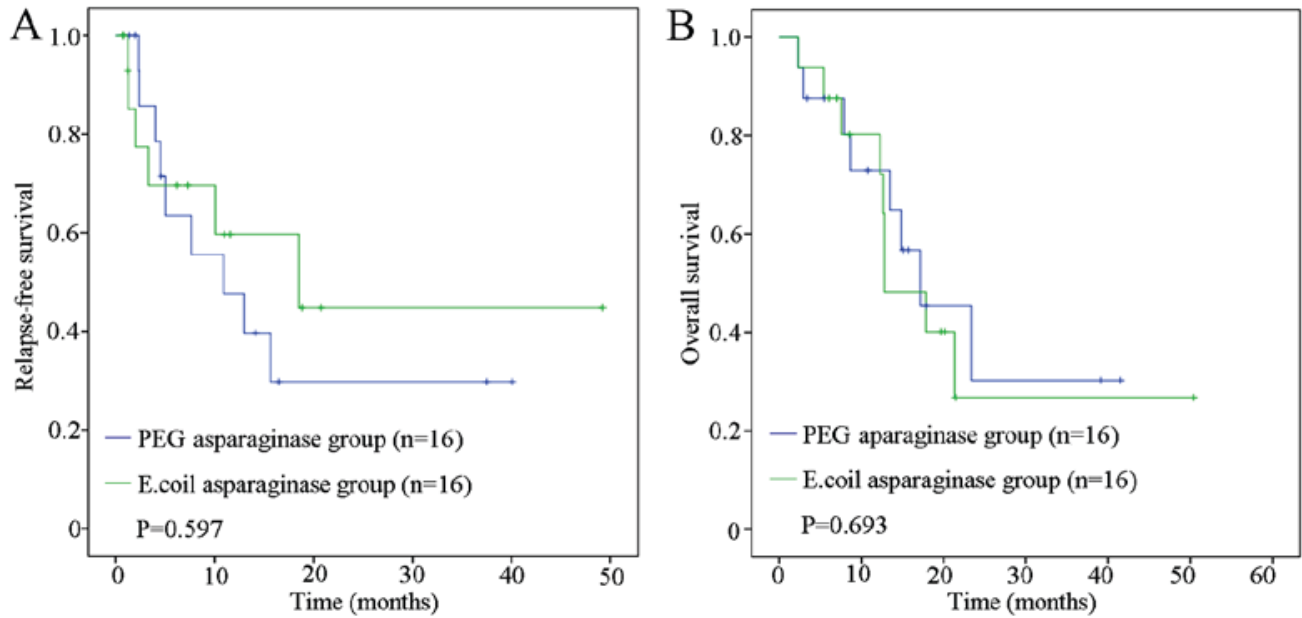

Figure 3. Kaplan-Meier estimates of RFS and OS in patients $\geq 35$ years old years old. (A) RFS in patients $\geq 35$ years old. (B) OS in patients $\geq 35$ years old. RFS, relapse-free survival; OS, overall survival; PEG asparaginase, polyethylene glycol-conjugated asparaginase.

have revealed a more rapid lymphoblast clearance, a lower titer of antibody and prolonged enzyme activity in pediatric patients with ALL undergoing induction therapy with PEG asparaginase compared with E. coli asparaginase $(22,23)$.

The present study compared the efficacy and safety of PEG asparaginase with E. coli asparaginase in adolescent and adult patients with ALL. The results demonstrated that the PEG asparaginase and E. coli asparaginase groups had satisfactory CR rates (95.65 vs. $90.79 \%$ ) following induction therapy. The median times taken to achieve CR were similar at 30 days in the PEG asparaginase group and 29.5 days in the E. coli asparaginase group. When taking long-term efficacy into consideration, the present study followed up on these patients and identified no significant difference in median RFS time (10.00 vs. 8.57 months) or median OS time (14.07 vs. 16.29 months) between the two groups. As age is an independent prognostic factor for patients with ALL, the present study considered various age subgroups in analyses and revealed that patients $<35$ years old in the PEG asparaginase group experienced a longer median RFS time compared with those in the E. coli asparaginase group (10.93 vs. 8.97 months;
$\mathrm{P}=0.037$ ), whereas no statistical significance was observed in median RFS or OS times among patients $\geq 35$ years old in the two groups.

Furthermore, patients treated with $E$. coli asparaginase demonstrated a significantly higher incidence of CNSL compared with those treated with PEG asparaginase ( 27.63 vs. $10.87 \%$; $\mathrm{P}=0.028$ ) during the consolidation phase. This suggested that PEG asparaginase served a potential role in preventing CNSL compared with E. coli asparaginase. Patients with higher cerebrospinal fluid (CSF) asparagine levels $(>1 \mu \mathrm{mol} / \mathrm{l})$ during asparaginase treatment were more likely to experience isolated CNS relapse (24). PEG asparaginase and $E$. coli asparaginase may induce a decrease in the asparagine level in the CSF $(14,24)$. Asparaginase cannot cross the blood-brain barrier or be detected in the CSF. However, it may deplete the asparagine in the CSF if there is an adequate expression level in the plasma $(22,25)$. Furthermore, the expression level of asparagine in the CSF was inversely associated with the titer of the anti-asparaginase antibody $(22,24,26,27)$. Hence, the present study hypothesized that the lower incidence of CNSL in the PEG asparaginase group may have contributed 
Table III. Adverse events during asparaginase-containing treatment.

\begin{tabular}{|c|c|c|c|}
\hline Event & $\begin{array}{l}\text { PEG asparaginase } \\
\qquad(\mathrm{n}=46)\end{array}$ & $\begin{array}{l}\text { E. coli asparaginase } \\
\qquad(\mathrm{n}=76)\end{array}$ & P-value \\
\hline Allergy, n (\%) & $1(2.17)$ & $0(0.00)$ & 0.377 \\
\hline Grade III-IV liver dysfunction, n (\%) & $10(21.74)$ & $9(11.84)$ & 0.144 \\
\hline Renal function damage, n (\%) & 0 & 0 & - \\
\hline Pancreatic lesion, n (\%) & $3(6.52)$ & $4(5.26)$ & 1.000 \\
\hline Bleeding event, n (\%) & $4(8.70)$ & $3(3.95)$ & 0.424 \\
\hline Maximal PT (range), sec & $16.00(10.50-49.00)$ & $15.00(11.4-24.00)$ & 0.214 \\
\hline Maximal APTT (range), sec & $50.05(26.50-100.70)$ & $45.85(30.6-90.20)$ & 0.250 \\
\hline Minimal Fbg (range), g & $1.01(0.15-2.36)$ & $1.00(0.25-1.90)$ & 0.403 \\
\hline $\begin{array}{l}\text { Beginning of coagulation dysfunction } \\
\text { (range), days }\end{array}$ & $3.50(1-14)$ & $4.00(1-14)$ & 0.462 \\
\hline $\begin{array}{l}\text { Duration of coagulation dysfunction, } \\
\text { days }\end{array}$ & $9.80 \pm 5.51$ & $6.80 \pm 4.21$ & 0.002 \\
\hline Grade of granulocytopenia, n (\%) & & & 0.298 \\
\hline I & $1(2.27)$ & $1(1.45)$ & \\
\hline II & $0(0)$ & $1(1.45)$ & \\
\hline III & $1(2.27)$ & $5(7.25)$ & \\
\hline IV & $42(95.46)$ & $62(89.85)$ & \\
\hline Duration of agranulocytosis, days & $18.89 \pm 8.79$ & $12.03 \pm 8.34$ & $<0.001$ \\
\hline Grade of erythrocytopenia (\%) & & & 0.068 \\
\hline 0 & $1(2.27)$ & $0(0)$ & \\
\hline I & $0(0)$ & $1(1.45)$ & \\
\hline II & $3(6.82)$ & $9(13.04)$ & \\
\hline III & $35(79.55)$ & $58(84.06)$ & \\
\hline IV & $5(11.36)$ & $1(1.45)$ & \\
\hline Grade of thrombopenia (\%) & & & 0.138 \\
\hline 0 & $2(4.55)$ & $6(8.69)$ & \\
\hline I & $1(2.27)$ & $2(2.90)$ & \\
\hline II & $2(4.55)$ & $4(5.80)$ & \\
\hline III & $5(11.36)$ & $13(18.84)$ & \\
\hline IV & $34(77.27)$ & $44(63.77)$ & \\
\hline $\begin{array}{l}\text { Duration of platelet level }<20 \mathrm{~g} / 1 \\
\text { (range), days }\end{array}$ & $2(0-34)$ & $1(0-21)$ & 0.508 \\
\hline Grade IV-V infection, $\mathrm{n}(\%)^{\mathrm{a}}$ & $10(22.73)$ & $5(7.25)$ & 0.018 \\
\hline Infection-associated mortality, $\mathrm{n}(\%)^{\mathrm{a}}$ & $1(2.27)$ & $0(0.00)$ & 0.389 \\
\hline
\end{tabular}

${ }^{a}$ Adverse effects of myelosuppression and infection were evaluated only in patients who achieve CR following VDLP therapy (44 in the PEG asparaginase group and 69 in the E. coli asparaginase group). PT, thromboplastin time; APTT, partial thromboplastin time; Fbg, fibrinogen; CR, complete remission; VDLP, vincristine, daunorubicin, L-asparagine and prednisone; E. coli, Escherichia coli.

to the improved activity of the asparaginase. Numerous factors, including pharmacological factors, asparaginase clearance and immunological factors, such as antibody formation, influence the activity of asparaginase. Firstly, the half-life of PEG asparaginase $(\sim 1$ week) is significantly longer compared with that of $E$. coli ( 1.25 days). It is uncertain whether the efficacy of preventing CNSL is associated with the half-life of asparaginase. Moghrabi et al (7) previously compared the efficacy of Erwinia asparaginase $\left(\mathrm{t}_{1 / 2} \sim 0.65\right.$ days $)$ and $E$. coli asparaginase $\left(\mathrm{t}_{1 / 2} \sim 1.24\right.$ days) and revealed that pediatric patients with ALL treated with $E$. coli asparaginase had fewer CNSL relapses (7). Secondly, patients treated with native $E$. coli asparaginase have been shown to demonstrate a higher titer of antibodies compared with those treated with PEG asparaginase $(14,23)$. Antibodies tend to diminish the efficacy of asparaginase by neutralizing its activity (resulting in faster asparaginase clearance) and high expression levels of anti-asparaginase antibodies are associated with shorter durations of asparagine depletion. Therefore, PEG asparaginase may strengthen the anti-leukemia effect in the CNS due to its advantages of extended effectiveness and lower immunogenicity.

Furthermore, a higher titer of anti-asparaginase antibodies results in a more rapid clearance of the agent and glucocorticoid. It has been reported that patients with ALL who test 
positive for anti-asparaginase antibodies experience a more rapid clearance of dexamethasone and a lower area under the curve in the plasma (28). Furthermore, multivariate analysis has demonstrated that a rapid clearance of glucocorticoid and a positive anti-asparaginase antibody status are independent risk factors in CNSL relapse (28). Due to its impact on hepatic synthesis, asparaginase may decrease the synthesis of CYP3A cytochrome $\mathrm{P} 450$, which is responsible for the metabolism of glucocorticoid (28). Based on these findings, patients who develop anti-asparaginase antibodies are disadvantaged, as they have less exposure to the two agents critical to ALL treatment. Due to the small number of cases considered in the present study, the difference in CNSL incidence may be associated with a sample error rather than PEG asparaginase treatment. Therefore, a larger population must be examined to verify the potential role of PEG asparaginase in preventing CNSL.

The present study also evaluated the safety of the two asparaginase preparations. Toxic events, including allergy, grade III-IV liver dysfunction, renal function damage and pancreatic lesions, were similar between the two groups. A prolonged duration of coagulation dysfunction $(9.80 \pm 5.51$ vs. $6.80 \pm 4.21$ days; $\mathrm{P}=0.002$ ) was observed in the $\mathrm{PEG}$ asparaginase group; however, it did not increase bleeding events (Table III). Patients treated with PEG asparaginase also had longer durations of agranulocytosis (18.89 \pm 8.79 vs. $12.03 \pm 8.34$ days; $\mathrm{P}<0.01)$ and a higher grade IV-V infection rate $(22.73$ vs. $7.25 \%$; $\mathrm{P}=0.018$ ) compared with those treated with $E$. coli asparaginase. Nevertheless, there was no statistical difference in infection-associated mortalities between the two groups (Table III). The present study suggested that this finding may be attributed to the prolonged duration of agranulocytosis. The coagulation dysfunction was attributable to the longer half-life and decreased immunogenicity of the PEG asparaginase group. This revealed a more evident effect on hepatic function, which changed the pharmacokinetics of other chemotherapeutics and inhibited the synthesis of coagulation factors (29).

The toxicities of asparaginase can be divided into two main categories: Those associated with immunogenicity, including hypersensitivity reactions (urticaria, rash, serum sickness, bronchospasm and anaphylaxis) and those associated with the inhibition of protein synthesis, including liver dysfunction, pancreatitis and coagulation deficiency $(14,30)$. Patients with ALL may tolerate complications resulting from an inhibition of protein synthesis under supportive treatment (11). However, severe hypersensitivity reactions, including life-threatening anaphylaxis, require the urgent discontinuation of drug administration. Data from previous studies have demonstrated that the incidence of hypersensitivity reactions was $10 \%$ for PEG asparaginase patients and varied from $13-30 \%$ for $E$. coli asparaginase patients (22). The hypersensitivity reactions were relative to the formation of anti-asparaginase antibodies. In addition, 'silent inactivation' occurs when patients develop antibodies and experience no clinical reaction. Patients in these conditions may respond more poorly to the agent. The immunogenicity of asparaginase remains an issue complicating its clinical use. Studies have implied that the use of native $E$. coli asparaginase in induction induces a high rate and intensification of hypersensitivity (30\%) to PEG asparaginase among pediatric patients with ALL (31). Thus, PEG asparaginase should be used up front in induction rather than in consolidation. Given the immunogenicity of asparaginase, it is strongly recommended that the anti-asparaginase antibodies should be monitored. Detecting the status and expression level of patients' antibodies is more important for silent inactivation patients and serves a critical role in preventing the further use of inactive asparaginase preparations $(18,19)$.

In conclusion, PEG asparaginase was revealed to have comparable CR rates, and OS and RFS times with those of E. coli asparaginase in adolescent and adult patients with ALL. More importantly, PEG asparaginase revealed the potential to improve RFS times among patients $<35$ years old and prevent CNSL development. Although it had more of an effect on coagulation dysfunction and agranulocytosis, it did not increase toxicity-associated mortalities. When considering its convenience and improved enzyme activity, PEG asparaginase is a candidate for first-line treatment of adolescent and adult ALL. As the present study was a retrospective observation, a larger prospective clinical trial is required to further confirm these findings.

\section{Acknowledgements}

The present study was supported by the 2014 General Program of National Natural Science For Youth Foundation of China (grant no. 81400104). Some preliminary analysis for this study have been published previously in the Journal of Third Military Medical University (Vol. 38, No. 7, Apr. 15, 2016). This article is the subsequent one, which excludes the cases from the former sample, including those who died following induction therapy, those lost to follow-up and those not strictly treated according to the standard dosage or treatment cycle. Furthermore, new cases were included and an insight into the patients' subgroup follow-up analysis was included in this study.

\section{References}

1. Kawedia JD and Rytting ME: Asparaginase in Acute Lymphoblastic Leukemia. Clin Lymph Myelom Leukem 14 (Suppl): S14-S17, 2014.

2. Shrivastava A, Khan AA, Khurshid M, Kalam MA, Jain SK and Singhal PK: Recent developments in L-asparaginase discovery and its potential as anticancer agent. Crit Rev Oncol Hematol 100: $1-10,2016$.

3. Marinescu C, Vlădăreanu AM and Mihai F: Acute lymphocytic leukemia in adults. Pathologic features and prognosis. Rom J Intern Med 53: 31-36, 2015.

4. Cooper SL and Brown PA: Treatment of pediatric acute lymphoblastic leukemia. Pediatr Clin North Am 62: 61-73, 2015.

5. Amylon MD, Shuster J, Pullen J, Berard C, Link MP, Wharam M, Katz J, Yu A, Laver J, Ravindranath Y, et al: Intensive high-dose asparaginase consolidation improves survival for pediatric patients with $\mathrm{T}$ cell acute lymphoblastic leukemia and advanced stage lymphoblastic lymphoma: A Pediatric Oncology Group study. Leukemia 13: 335-342, 1999.

6. Silverman LB, Gelber RD, Dalton VK, Asselin BL, Barr RD, Clavell LA, Hurwitz CA, Moghrabi A, Samson Y, Schorin MA, et al: Improved outcome for children with acute lymphoblastic leukemia: Results of Dana-Farber Consortium Protocol 91-01. Blood 97: 1211-1218, 2001.

7. Moghrabi A, Levy DE, Asselin B, Barr R, Clavell L, Hurwitz C, Samson Y, Schorin M, Dalton VK, Lipshultz SE, et al: Results of the Dana-Farber Cancer Institute ALL Consortium Protocol 95-01 for children with acute lymphoblastic leukemia. Blood 109: 896-904, 2007

8. Huguet F, Leguay T, Raffoux E, Thomas X, Beldjord K, Delabesse E, Chevallier P, Buzyn A, Delannoy A, Chalandon Y, et al: Pediatric-inspired therapy in adults with Philadelphia chromosome-negative acute lymphoblastic leukemia: The GRAALL-2003 study. J Clin Oncol 27: 911-938. 2009. 
9. Stock W, La M, Sanford B, Bloomfield CD, Vardiman JW, Gaynon P, Larson RA and Nachman J; Children's Cancer Group; Cancer and Leukemia Group B studies: What determines the outcomes for adolescents and young adults with acute lymphoblastic leukemia treated on cooperative group protocols? A comparison of Children's Cancer Group and Cancer and Leukemia Group B studies. Blood 112: 1646-1654, 2008.

10. Salzer WL, Devidas M, Shuster JJ, Wang C, Chauvenet A, Asselin BL, Camitta BM and Kurtzberg J; Children's Oncology Group: Intensified PEG-L-asparaginase and antimetabolite-based therapy for treatment of higher risk precursor-B acute lymphoblastic leukemia: A report from the Children's Oncology Group. J Pediatr Hematol Oncol 29: 369-375, 2007.

11. Stock W, Douer D, DeAngelo DJ, Arellano M, Advani A Damon L, Kovacsovics T, Litzow M, Rytting M, Borthakur G and Bleyer A: Prevention and management of asparaginase/pegasparaginase-associated toxicities in adults and older adolescents: Recommendations of an expert panel. Leuk Lymphoma 52: 2237-2253, 2011.

12. Kopeček J: Polymer-drug conjugates: Origins, progress to date and future directions. Adv Drug Deliver Rev 65: 49-59, 2013.

13. Pasut G, Sergi M and Veronese FM: Anti-cancer PEG-enzymes: 30 years old, but still a current approach. Adv Drug Deliv Rev 60: 69-78, 2008

14. Dinndorf PA, Gootenberg J, Cohen MH, Keegan P and Pazdur R: FDA drug approval summary: Pegaspargase (oncaspar) for the first-line treatment of children with acute lymphoblastic leukemia (ALL). Oncologist 12: 991-998, 2007.

15. Kurre HA, Ettinger AG, Veenstra DL, Gaynon PS, Franklin J, Sencer SF, Reaman GH, Lange BJ and Holcenberg JS: A pharmacoeconomic analysis of pegaspargase versus native Escherichia coli L-asparaginase for the treatment of children with standard-risk, acute lymphoblastic leukemia: The Children's Cancer Group study (CCG-1962). J Pediatr Hematol Oncol 24: 175-181, 2002

16. NCCN Clinical Practice Guidelines in Oncology (NCCN Guidelines)[S/OL]. Acute Lymphoblastic Leukemia. Version 1, 2015.http://www.nccn.org/professionals/physician_gls/f_guidelines.asp.

17. National Cancer Institute $[\mathrm{S} / \mathrm{OL}]$. Common Terminology Criteria for Adverse Events (CTCAE) Mar 4, 2010. http://evs.nci.nih gov/ftp1/CTCAE/CTCAE_4.03_2010-06-14_QuickReference_5x7. pdf.

18. Vrooman LM, Stevenson KE, Supko JG, O'Brien J, Dahlberg SE Asselin BL, Athale UH, Clavell LA, Kelly KM, Kutok JL, et al: Postinduction dexamethasone and individualized dosing of Escherichia coli L-asparaginase each improve outcome of children and adolescents with newly diagnosed acute lymphoblastic leukemia: Results from a randomized study-Dana-Farber Cancer Institute ALL Consortium Protocol 00-01. J Clin Oncol 31: 1202-1210, 2013

19. Panosyan EH, Seibel NL, Martin-Aragon S, Gaynon PS, Avramis IA, Sather H, Franklin J, Nachman J, Ettinger LJ, La M, et al: Asparaginase antibody and asparaginase activity in children with higher-risk acute lymphoblastic leukemia: Children's Cancer Group Study CCG-1961. J Pediatr Hematol Oncol 26: 217-226, 2004

20. Rytting M: Peg-asparaginase for acute lymphoblastic leukemia. Expert Opin Biol Ther 10: 833-839, 2010.
21. Thomas X, Cannas G, Chelghoum Y and Gougounon A: Therapeutic alternatives to native L-asparaginase in the treatment of adult acute lymphoblastic leukemia. Bull Cancer 97: 1105-1117, 2010 (In French).

22. Graham ML: Pegaspargase: A review of clinical studies. Adv Drug Deliv Rev 55: 1293-1302, 2003.

23. Avramis VI, Sencer S, Periclou AP, Sather H, Bostrom BC, Cohen LJ, Ettinger AG, Ettinger LJ, Franklin J, Gaynon PS, et al: A randomized comparison of native Escherichia coli asparaginase and polyethylene glycol conjugated asparaginase for treatment of children with newly diagnosed standard-risk acute lymphoblastic leukemia: A Children's Cancer Group study. Blood 99: 1986-1994, 2002

24. Panetta JC, Gajjar A, Hijiya N, Hak LJ, Cheng C, Liu W, Pui $\mathrm{CH}$ and Relling MV: Comparison of native E. coli and PEG asparaginase pharmacokinetics and pharmacodynamics in pediatric acute lymphoblastic leukemia. Clin Pharmacol Ther 86: 651-658, 2009.

25. Sirvent N, Suciu S, Rialland X, Millot F, Benoit Y, Plantaz D, Ferster A, Robert A, Lutz P, Nelken B, et al: Prognostic significance of the initial cerebro-spinal fluid (CSF) involvement of children with acute lymphoblastic leukaemia (ALL) treated without cranial irradiation: Results of European Organization for Research and Treatment of Cancer (EORTC) Children Leukemia Group study 58881. Eur J Cancer 47: 239-247. 2011.

26. Pieters R, Hunger SP, Boos J, Rizzari C, Silverman L, Baruchel A, Goekbuget N, Schrappe M and Pui CH: L-asparaginase treatment in acute lymphoblastic leukemia: A focus on Erwinia asparaginase. Cancer 117: 238-249. 2011.

27. Henriksen LT, Nersting J, Raja RA, Frandsen TL, Rosthøj S, Schrøder H and Albertsen BK; Nordic Society of Paediatric Haematology and Oncology (NOPHO) group: Cerebrospinal fluid asparagine depletion during pegylated asparaginase therapy in children with acute lymphoblastic leukaemia. Br J Haematol 166: 213-220, 2014.

28. Kawedia JD, Liu C, Pei D, Cheng C, Fernandez CA, Howard SC, Campana D, Panetta JC, Bowman WP, Evans WE, et al: Dexamethasone exposure and asparaginase antibodies affect relapse risk in acute lymphoblastic leukemia. Blood 119: 1658-1664, 2012

29. Merryman R, Stevenson KE, Gostic WN, Neuberg D II, O'Brien J, Sallan SE and Silverman LB: Asparaginase-associated myelosuppression and effects on dosing of other chemotherapeutic agents in childhood acute lymphoblastic leukemia. Pediatr Blood Cancer 59: 925-927, 2012.

30. Avramis VI and Tiwari PN: Asparaginase (native ASNase or pegylated ASNase) in the treatment of acute lymphoblastic leukemia. Int J Nanomedicine 1: 241-254, 2006.

31. Tong WH, Pieters R, Kaspers GJ, Te LD, Bierings MB, van den Bos C, Kollen WJ, Hop WC, Lanvers-Kaminsky C, Relling MV, et al: A prospective study on drug monitoring of PEGasparaginase and Erwinia asparaginase and asparaginase antibodies in pediatric acute lymphoblastic leukemia. Blood 123 : 2026-2033. 2014

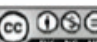

This work is licensed under a Creative Commons Attribution-NonCommercial-NoDerivatives 4.0 International (CC BY-NC-ND 4.0) License. 